\title{
Evaluation of physiotherapists as primary assessors of patients with musculoskeletal disorders seeking primary health care
}

\author{
Maria Landén Ludvigsson and Paul Enthoven
}

\section{Linköping University Post Print}

N.B.: When citing this work, cite the original article.

Original Publication:

Maria Landén Ludvigsson and Paul Enthoven, Evaluation of physiotherapists as primary assessors of patients with musculoskeletal disorders seeking primary health care, 2012, Physiotherapy, (98), 2, 131-137.

http://dx.doi.org/10.1016/j.physio.2011.04.354

Copyright: Elsevier http://www.elsevier.com/

Postprint available at: Linköping University Electronic Press

http://urn.kb.se/resolve?urn=urn:nbn:se:liu:diva-77318 
Title: Evaluation of physiotherapists as primary assessors of patients with musculoskeletal disorders seeking primary health care

\section{Authors:}

Maria Landén Ludvigsson ${ }^{1}$, RPT, MSc, Certified Specialist in Physiotherapy in Primary Health Care

Paul Enthoven ${ }^{2}, \mathrm{RPT}, \mathrm{PhD}$, Senior Lecturer

${ }^{1}$ Rehab Vast, Vc Brinken, County Council of Ostergotland, Sveavagen 32, SE-59136

Motala, Sweden. email: Maria.Landen.Ludvigsson@liu.se

${ }^{2}$ Department of Medical and Health Sciences, Division of Physiotherapy, Linköping University, SE-58183 Linköping, Sweden. email: paul.enthoven@liu.se

\section{Corresponding author}

\begin{tabular}{|l|l|}
\hline Name & Dr. Paul Enthoven \\
\hline Department & Department of Medical and Health Sciences \\
\hline Institution & Linköping University \\
\hline Country & Sweden \\
\hline Tel & +46101037830 \\
\hline Mob & +46706104629 \\
\hline Fax & +46101031706 \\
\hline Email & paul.enthoven@liu.se \\
\hline
\end{tabular}

Word Count: $\quad 243$ words (Abstract)

3266 words (Main body of paper) 


\section{ABSTRACT}

Objectives To evaluate primary physiotherapist assessment and management of patients with musculoskeletal disorders in primary care. Another aim was to compare patient satisfaction with primary assessment by either a physiotherapist or a general practitioner (GP).

Design An observational, retrospective cohort study reviewing medical records, and a separate consecutive non-randomized study of patient satisfaction.

Setting Health care centre in primary care.

Participants 432 patients with musculoskeletal disorders, primarily assessed by a physiotherapist. 51 of these patients and 42 patients assessed by a GP answered a patient satisfaction questionnaire.

Interventions Primary assessment and management of patients with musculoskeletal disorders.

Main outcome measures Data from medical records including a 3-month follow-up, and patient satisfaction questionnaire.

Results Eighty-five percent of patients (367/432) did not need to see a GP. Serious pathologies were found among the 6\% (26/432) of the patients whom the physiotherapist referred to a GP, while none were found among the other 9\% (39/432) who later returned for a GP appointment. Patients assessed by a physiotherapist were more satisfied with the information received about their disorders and about self-care than those assessed by a GP. They also had higher confidence in the physiotherapist's ability to assess their disorder $(\mathrm{p}<0.002)$.

Conclusion Physiotherapists can be considered primary assessors of patients with musculoskeletal disorders in primary care as few patients needed additional assessment by a GP, patients with confirmed serious pathologies had been identified by the physiotherapist, and the patients were satisfied with the assessment by the physiotherapist. 
Keywords: Physiotherapy; Primary health care; Direct access; Musculoskeletal; General Practitioner; Patient satisfaction 


\section{INTRODUCTION}

Musculoskeletal pain accounts for two-thirds of all pain disorders handled in Swedish primary health care clinics [1], and in the UK musculoskeletal conditions are associated with the second highest rates of sickness certification [2]. Troublesome pain over the previous four weeks has been reported to be most common in the lower back (25\%), neck (18\%), knee (17\%), and shoulder (17\%) in a cross-sectional UK survey of adults registered with general practices [3]. Total estimated expenditures on patients with spine problems have increased by $65 \%$ in less than a decade, a more rapid increase than overall health expenditures in the USA [4].

Several studies demonstrate the competence of physiotherapists to assess musculoskeletal disorders [5-8], and both general practitioners (GPs) and physiotherapists have reported high levels of comfort with, and confidence in physiotherapists as first point of contact practitioners [9]. Additionally, assessments at physiotherapy clinics have been found to be cost-effective [5-6, 8]. Patients with soft tissue injuries presenting to accident and emergency departments can often be handled by a physiotherapist without seeing a physician [10-12]. Decreased waiting times and length of stay for patients, without any adverse effects, have also been reported as a result of physiotherapists working in emergency departments as first point of contact [12]. Patients seen by a physiotherapist have been shown to be more satisfied with care than those seen by a physician at emergency and orthopaedic departments [8,10-11]. However to our knowledge no studies have compared patient satisfaction with primary assessment by either a physiotherapist or a GP in primary care.

In the UK, direct access to physiotherapists has been suggested to lead to a reduction of GP work load [13]. In Sweden, direct access or self-referral to physiotherapy is possible, but it is 
still common for people to initially see a GP. Due to shortage of GP resources the need to make more GP resources available for medical conditions that require specific GP competence, has led to new solutions. One of them is that persons seeking care for musculoskeletal problems can be allocated to primary assessment by a physiotherapist instead of a GP at some primary health care centres. However, little is known about possible consequences of this policy.

One aim of this study was to evaluate primary physiotherapist assessment and management of patients with musculoskeletal disorders in primary care. Another aim was to compare patient satisfaction with primary assessment by either a physiotherapist or a GP.

\section{METHODS}

\section{Setting}

The study was carried out at a health care centre in Sweden, including a GP surgery, and an ordinary physiotherapy clinic. An extra resource, the Physiotherapy Assessment Clinic (PAC) providing primary assessment of musculoskeletal disorders by physiotherapists instead of GPs was also available for approximately 5 hours per week. Primary assessment is defined as first appointment, enabling both history-taking and physical examination, in this study. Most persons contacting the health care centre in need of assessment of musculoskeletal disorders were allocated by nurses to the GP surgery, and a minority was allocated to the PAC instead. Persons who clearly needed a GP intervention e.g. due to suspicion of other diseases causing their problems or needing certain certificates, were to be scheduled with a GP. Otherwise, there were no restrictions regarding allocation. Five physiotherapists, all with at least three years experience and with further education in areas such as orthopaedic manual therapy and the McKenzie Method [14] worked part-time at the PAC during the study period. At the 
ordinary physiotherapy clinic patients in need of further physiotherapy after assessment at the PAC were treated, as well as for example self-referred patients. At the GP surgery four out of five participating physicians were registered GPs with several years of experience. One physician was not yet fully qualified as a GP, but in this study all physicians are referred to as GPs. The nurses were use to handling initial assessment and advice, mainly by telephone, of all types of patients in primary care. They had received information about physiotherapy through close cooperation over the preceding years, and had continuous contact with the physiotherapists, with whom they could discuss patients and symptoms.

\section{Study design}

The study consists of two parts (Figure 1). Part one is an observational, retrospective cohort study reviewing the joint physiotherapist and GP medical records of patients who had visited the PAC, including a three-month follow up. Part two is a non-randomized study in which consecutive patients with musculoskeletal disorders at the PAC and at the GP surgery were invited to fill out a questionnaire concerning satisfaction with care.

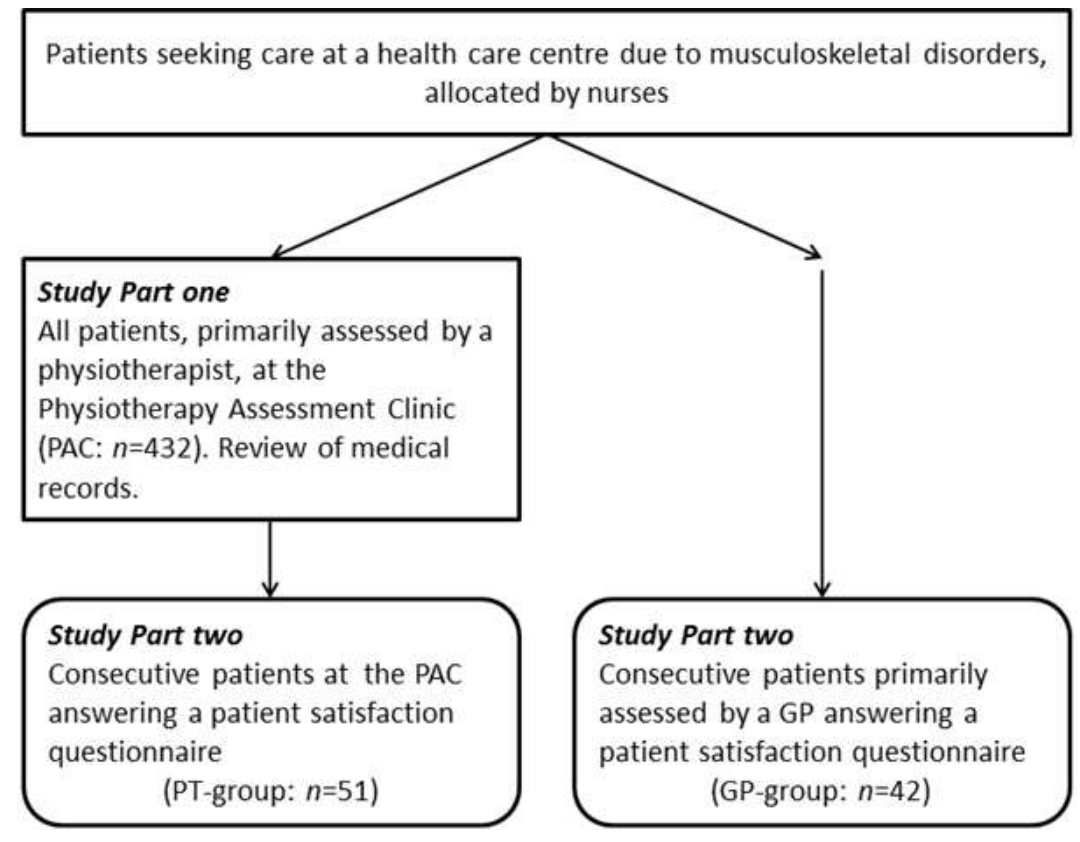

Figure 1. Design and flow of participants in the two parts of the study. PAC, Physiotherapy Assessment Clinic; GP, general practitioner. 


\section{Participants}

Part one: Management at the PAC and 3-month follow-up

432 persons contacting the health care centre (not the ordinary physiotherapy clinic) with musculoskeletal disorders were allocated by nurses to the PAC between January 2004 to June 2007.

\section{Part two: patient satisfaction}

Of the main cohort of 432 patients, a sub-cohort of all 56 consecutive patients visiting the PAC between January to June 2007 (PT-group), and all 54 consecutive patients visiting the GP surgery in April and May 2007, due to musculoskeletal disorders only, (GP-group) were asked to fill out a questionnaire regarding patient satisfaction (Figure 1). Patients under the age of 18 without parental consent or individuals unable to understand Swedish were to be excluded from this second part of the study, but no exclusions were necessary.

\section{Outcome measures}

\section{Part one: Management at the PAC and 3-month follow-up}

Data from joint GP and physiotherapy medical records of all 432 patients visiting the PAC during $3 \frac{1}{2}$ years were included. Apart from demographic data and diagnoses, variables requiring cooperation with a physician, such as medical certificates, prescriptions or referrals for X-rays in connection with the physiotherapy assessment were registered. In Sweden, medical certificates issued by physicians are required for sick-listing. Treatment given at the PAC, referrals to further physiotherapy, referral by the physiotherapist to a GP, and previous health care appointments for the same kind of disorder were also registered. A 3-month follow up was conducted, and the number of patients who returned for additional GP appointments and suspected occurrence of serious underlying pathology for the disorder were registered. 
Serious pathology included systemic diseases, fractures, total ruptures, tumors, extensive loss of neurologic functions, including cauda equina syndrome due to disc herniations.

\section{Part two: patient satisfaction}

56 consecutive patients visiting the PAC and 54 consecutive patients visiting the GP surgery were asked to fill out questionnaires collecting information concerning demographic data, duration and location of current disorder, previous experience of care from a GP or physiotherapist, satisfaction with care, and health-related quality of life (EQ-5D). The reliable and valid generic EQ-5D questionnaire consists of five questions converted into a summary index and a visual analogue scale (EQ VAS) recording the respondent's self-rated health on a scale from 0 to 100 [15-16]. The questions on satisfaction with care included five-grade scales of perceived confidence in the ability of the physiotherapist/GP to assess the current disorders, receipt of sufficient information about their current disorder, self-care, and the individual's abilities to affect the current disorder. These questions were previously used within the local county council to investigate satisfaction with care (unpublished data), and the latter question was slightly modified to suit the purpose of this study. As the entire questionnaire was piloted in ten patients, with satisfying results, no changes were made before being used in this study.

\section{Statistical analysis}

Descriptive statistics were used. To compare groups, the Mann-Whitney U-test, Chi Square test, Fisher's exact test, and t-test were used. The significance level was set at $\mathrm{p}<0.05$. 


\section{RESULTS}

\section{Part one: Management at the PAC and 3-month follow-up}

Of the total 432 patients attending the PAC, 80\% (345/432) were of employable age (20-65 years old). The most frequent diagnoses were low back pain and neck pain. Table 1 reports additional patient characteristics and interventions at the visit, other than history taking and physical examination. In $94 \%$ of patients (406/432), the physiotherapist saw no present need for the patient to be assessed by a GP. Some of the patients $(32 / 432,7 \%)$ were considered in need of interventions that were unavailable to the physiotherapist, such as x-rays, prescriptions, and/or medical certificates enabling sick listing of a few weeks duration. Through close cooperation between the GPs and physiotherapist, this could be solved without the patient needing an additional appointment with a GP. However, in $6 \%$ of the cases (26/432) an assessment by a GP was considered necessary, mainly due to suspicion of other diseases/underlying serious pathology or the need of a medical certificate for sick-listing lasting more than a few weeks. Among these patients, serious pathology, as previously specified, was found.

At the follow-up three months after the initial assessment, 85\% (367/432) of the patients had not returned to see a GP for the same disorder. In addition to the $6 \%(26 / 432)$ of the patients initially referred to a GP by the physiotherapist as mentioned above, another 9\% (39/432) of the patients had visited a GP at the health care centre due to the same problem. This was either due to the patient's personal wish, or other circumstances, e.g. need of medical certificates enabling further sick listing. Of these 39 (39/432, 9\%) patients, no serious pathologies as previously specified, were detected by the GP. Thus all patients found to have a serious underlying pathology within 3 months after the initial assessment $(17 / 432,4 \%)$ were identified at baseline by the physiotherapist. There was no difference in gender, being of 
employable age or not, or most frequent diagnoses between the patients receiving an additional assessment by a GP and those who did not.

\section{Part two: Patient satisfaction}

Of the main cohort of 432 patients visiting the PAC, a consecutive sub-cohort of 56 (= PTgroup) were asked to fill out the questionnaire, and $51(51 / 56,91 \%)$ agreed to do so. There were no differences between the patients in the sub-cohort who answered the questionnaires (PT-group, $n=51)$ and all patients in the main cohort at the PAC $(n=432)$ in terms of patient characteristics, diagnosis, duration of disorder, and measures taken, as seen in Table 1. The PT-group can thus be assumed to be representative of the whole population assessed at the PAC.

At the GP surgery, 54 consecutive patients were invited to participate, 42 patients (42/54, $78 \%=$ GP-group) of whom accepted. The patients in the PT-group were more often women and reported better general health (EQ-5D and EQ VAS) compared to the patients in the GPgroup. Otherwise there were no differences in patient characteristics between the groups (see

Table 2). The most common interventions by the GP in this group were medical prescriptions (25/42, 60\%), x-rays $(12 / 42,29 \%)$, laboratory tests $(10 / 42,24 \%)$, and medical certificates $(7 / 42,17 \%)$.

There were significant differences in patient satisfaction between the two groups in all questionnaire items (Figure 2). The response rate for all items was 95\% or higher (40/42, 95\%) in the GP-group, and 98\% or higher $(50 / 51,98 \%)$ in the PT-group. Patients assessed by a physiotherapist were more satisfied with sufficiency of information about the current disorder, information about self-care, and their own ability to affect the current disorder than those assessed by a GP. Significantly more patients in the PT-group expressed complete 


\section{Table 1}

Patient characteristics and management at the Physiotherapy Assessment Clinic.

Comparison between the main cohort and the sub-cohort (PT-group ${ }^{\mathrm{a}}$ ).

\begin{tabular}{|c|c|c|c|}
\hline $\begin{array}{l}\text { Medical Record Exploration } \\
\text { Physiotherapy Assessment Clinic }\end{array}$ & $\begin{array}{l}\text { All } \\
n=432\end{array}$ & $\begin{array}{l}\text { PT-group } \\
\mathrm{n}=51\end{array}$ & p value \\
\hline \multicolumn{4}{|l|}{ Patient characteristics } \\
\hline Age, $\mathrm{m}$ (range) SD & $45(3-89) 18$ & $46(10-83) 20$ & 0.845 \\
\hline Female gender & $260(60)$ & $35(69)$ & 0.242 \\
\hline Previously sought care for similar disorder & $244(57)$ & $24(47)$ & 0.200 \\
\hline Duration of current problems & & & 0.094 \\
\hline 0-4 weeks & $173(40)$ & $15(29)$ & \\
\hline $1-3$ months & $95(22)$ & $11(22)$ & \\
\hline$>3$ months & $163(38)$ & $25(49)$ & \\
\hline \multicolumn{4}{|l|}{ ICD-10 diagnosis } \\
\hline Low back & $167(39)$ & $16(31)$ & 0.310 \\
\hline Neck & $109(25)$ & $11(21)$ & 0.567 \\
\hline Shoulder & $22(5)$ & $4(8)$ & 0.341 \\
\hline Thoracic & $21(5)$ & $3(6)$ & 0.731 \\
\hline Knee & $34(8)$ & $7(14)$ & 0.179 \\
\hline Other & $79(18)$ & $10(20)$ & 0.818 \\
\hline \multicolumn{4}{|l|}{ Management } \\
\hline Advice & $429(99)$ & $51(100)$ & 1.000 \\
\hline Manual treatment/electrotherapy & $84(19)$ & $8(16)$ & 0.518 \\
\hline Aids & $35(8)$ & $4(8)$ & 0.950 \\
\hline Referral to further physiotherapy & $117(27)$ & $15(29)$ & 0.724 \\
\hline $\begin{array}{l}\text { Patients needing interventions by a GP } \\
\text { but without GP appointment }{ }^{\text {b }}\end{array}$ & $32(7)$ & $2(4)$ & 0.357 \\
\hline GP referral & $26(6)$ & $2(4)$ & 0.545 \\
\hline
\end{tabular}

Figures are numbers (percentages) if not stated otherwise

${ }^{\text {a }}$ PT-group: Patients who answered a patient satisfaction questionnaire.

${ }^{\mathrm{b}}$ included $\mathrm{x}$-rays, prescription of medication, or medical certificates enabling short-term sick listing. 


\section{Table 2}

Self-reported patient characteristics and additional GP appointment according medical records. Comparison between the PT-group ${ }^{\mathrm{a}}$ and the GP-group ${ }^{\mathrm{b}}$.

\begin{tabular}{|c|c|c|c|c|c|}
\hline \multicolumn{6}{|l|}{ Patient characteristics } \\
\hline & $\mathbf{n}=$ & PT group & $\mathbf{n}=$ & GP group & p value \\
\hline Age, mean (range) SD & 51 & $45(10-84) 20$ & 42 & $51(14-86) 18$ & 0.132 \\
\hline Female gender & 51 & $35(69)$ & 42 & $18(43)$ & 0.012 \\
\hline EQ 5D index mean (SD) & 51 & $0.65(0.22)$ & 38 & $0.51(0.30)$ & 0.014 \\
\hline EQ VAS, mean (SD) & 49 & $67(18)$ & 38 & $56(19)$ & 0.006 \\
\hline $\begin{array}{l}\text { Previous experience of } \\
\text { visiting a GP }\end{array}$ & 50 & $49(98)$ & 42 & $38(91)$ & 0.174 \\
\hline $\begin{array}{l}\text { Previous experience of } \\
\text { visiting a PT }\end{array}$ & 51 & $27(53)$ & 42 & $25(60)$ & 0.525 \\
\hline Duration of current problems & 51 & & 42 & & 0.940 \\
\hline $0-4$ weeks & & $9(18)$ & & $10(24)$ & \\
\hline $1-3$ months & & $18(35)$ & & $11(26)$ & \\
\hline$>3$ months & & $24(47)$ & & $21(50)$ & \\
\hline \multicolumn{6}{|l|}{ Pain localization ${ }^{\mathrm{c}}$ : } \\
\hline Neck pain & 51 & $13(26)$ & 42 & $11(26)$ & 0.939 \\
\hline Shoulder/arm & 51 & $22(43)$ & 42 & $21(50)$ & 0.509 \\
\hline Low back & 51 & $16(31)$ & 42 & 8 (19) & 0.176 \\
\hline Hip/leg pain & 51 & $13(26)$ & 42 & $16(38)$ & 0.192 \\
\hline $\begin{array}{l}\text { Patients with additional GP } \\
\text { appointment within } 3 \text { months }\end{array}$ & 51 & $6(12)$ & 42 & $20(48)$ & $<0.001$ \\
\hline
\end{tabular}

Figures are numbers (percentages) if not stated otherwise.

${ }^{\text {a }}$ PT-group: Patients assessed by a physiotherapist

${ }^{\mathrm{b}}$ GP-group: Patients assessed by a general practitioner

${ }^{\mathrm{c}}$ Patients could report more than one pain localization. 


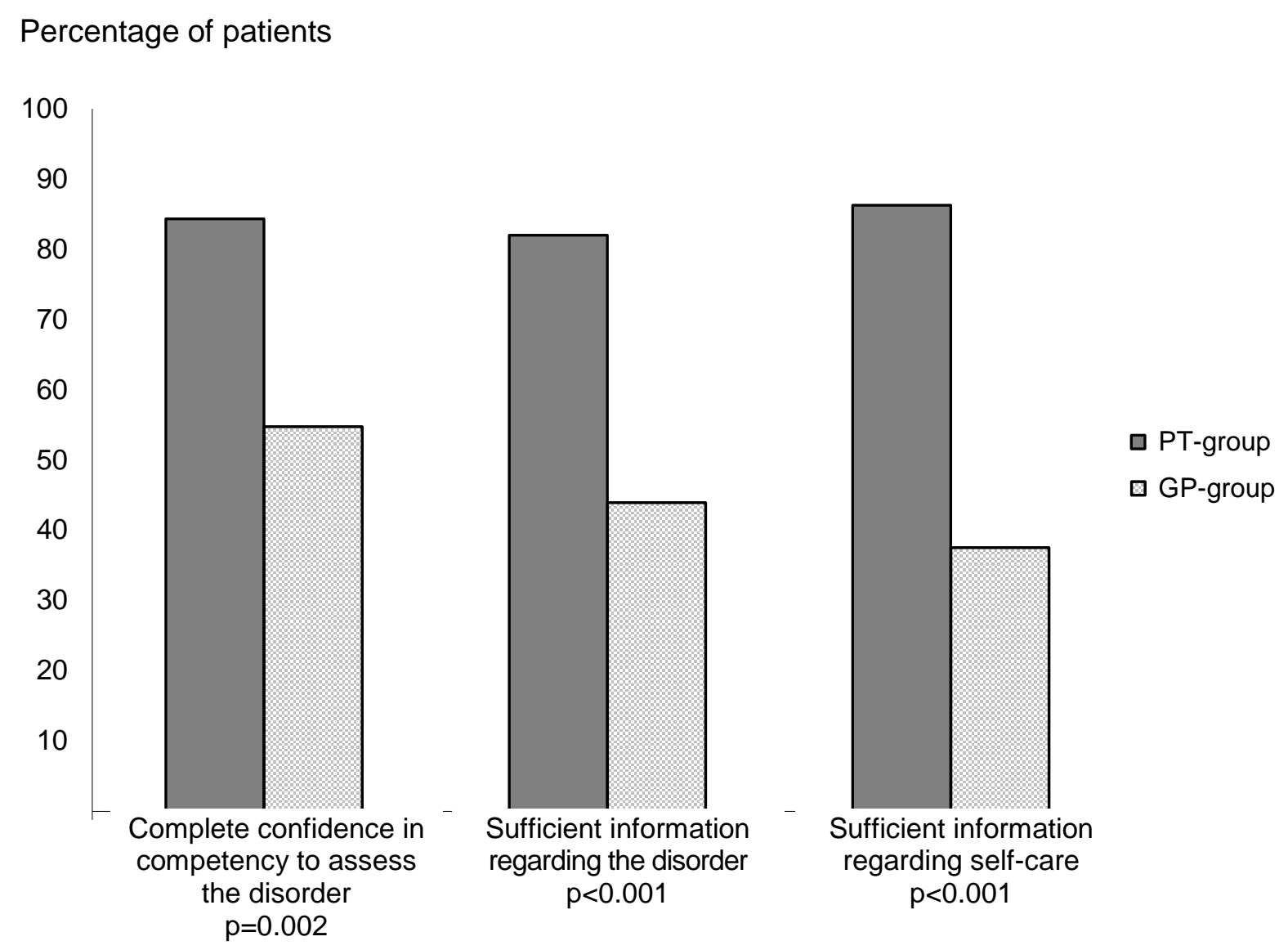

Figure 2. Patients' confidence in the assessor and satisfaction with information provided in those assessed by a physiotherapist (PT-group) or by a general practitioner (GP-group).

confidence in the physiotherapist's ability to assess their disorders versus patients in the GPgroup expressing complete confidence in the ability of the GP. Within 3 months after the initial assessment, 48\% (20/42) of the patients assessed by a GP returned for another GP appointment at the health care centre due to the same disorder. This was greater than the $12 \%$ $(6 / 51)$ of the patients assessed by a physiotherapist who returned for a GP appointment due to the same disorder $(\mathrm{p}<0.001)$.

\section{DISCUSSION}

The present study shows that many patients seeking primary health care for musculoskeletal disorders, who traditionally would have been booked for assessment and treatment by a GP, 
could be adequately assessed and managed by a physiotherapist. Furthermore, patients were satisfied with having a primary assessment by a physiotherapist. One goal of the PAC was to make more GP resources available for medical conditions in need of assessment and initial management that required GP competence. At the 3-month follow-up after assessment at the PAC, $85 \%$ (367/432) of the patients had not sought additional assessment by a GP for the same disorder. This suggests that being assessed by a physiotherapist was appropriate for the majority of these patients. Serious pathologies were found among the 6\% (26/432) of the patients whom the physiotherapist referred to a GP, but no such causes were found among the other $9 \%$ (39/432) of the patients who chose to return for a GP appointment. Although previously undiagnosed serious pathologies are rare in patients seeking primary care for musculoskeletal conditions such as back pain, it is important that they be identified [17]. The physiotherapists referred 6\% (26/432) of the patients to a GP. This is in line with, but somewhat lower than a large study in Scotland, where physiotherapists discharged about 10\% of patients with low back pain for further medical review ([18]. The fact that patients did not need to see a GP for interventions such as X-rays, short-term medical certificates, or prescriptions saves time for both patients and GPs. A fundamental requirement for enabling this is well-established cooperation between physiotherapists and GPs, as well as confidence in the competence of the physiotherapists. This cooperation has been developed over many years at this health care centre and might be a key factor in the success of the PAC. According to county council statistics, an appointment with a GP generally costs about twice as much as an appointment with a physiotherapist. Most physiotherapist appointments for patients with neck or back problems were longer than the GP appointments, but did not require assistance by additional staff, e.g. secretary, as the documentation was done by the physiotherapist within the time limit for the appointment. Previous studies show that an assessment by a physiotherapist costs considerably less [5-6, 8] or at least not more than an assessment by a 
physician [11]. Self-referral to physiotherapists rather than referrals by a GP may also generate lower costs of total episodes of care [19-20] and might have both patient and service benefits according to a UK governmental report [21].

The vast majority of the patients assessed by either a physiotherapist or a GP were satisfied with the assessment, but patients assessed by a physiotherapist were significantly more likely to be satisfied. This is in accordance with previous studies in which patients were more satisfied when assessed by a physiotherapist than by a physician $[6,10-11]$. There were no differences between the two groups with respect to most characteristics. However, the patients assessed by a GP reported worse general health (EQ-5D), which may have influenced the perceived quality of care. Higher satisfaction with care is reportedly related to higher health related quality of life [22]. It may also be one of the reasons why additional appointments with a GP were four times more common after an initial assessment by a GP than by a physiotherapist. However, there were significantly more women in the PT-group, and women generally have higher consultation rates [23], and have previously been shown to be less satisfied with primary care than men [24]. Despite this, patients in the PT-group were more satisfied. Choice of caregiver has previously been shown to be important for patients in primary care [25]. The patients in this study had not chosen to see a physiotherapist by selfreferral, but the reasons are unknown. Self-referred patients have been shown to be more satisfied with care, than those referred by a GP [26].

The main limitation of the study was that, due to practical reasons, the patients were not randomized to the PAC or the GP surgery, which might have led to an allocation bias. The patients assessed by a GP had worse self-reported general health which, as discussed above, might have influenced satisfaction with primary assessment. One reason might have been that the nurses subconsciously sent persons with worse general health or with multiple illnesses to 
a GP instead of to a physiotherapist, although according to their medical records they visited the GP surgery for musculoskeletal problems only. The setting was only one health care centre, and the results may not be generalisable to e.g. centres with different sizes, or with a different or no cooperation between physiotherapists and GPs. Furthermore, very few appointments, about five hours per week, were available at the PAC, compared to the much greater number of daily appointments available to the GPs. An increase in visiting hours at the PAC might improve the service even more.

More than $50 \%$ of patients had sought care at the health care centre due to similar problems previously. Enthoven et al (2004) [27] found that recurrence of neck pain or low back pain was common, as was seeking additional health care. The most common pain location in this study was the low back. More than $85 \%$ of patients who present to primary care have low back pain classified as nonspecific [28]. One explanation for why the patients were more satisfied and why fewer patients returned for an additional GP appointment after being assessed by a physiotherapist might be that the patients at the PAC have been further classified into subgroups since all physiotherapists in this study were working in accordance with the McKenzie and/or orthopaedic manual therapy methods. In these methods, classification into subgroups before treatment and giving advice is part of the protocol. Studies have shown that treatment might be more effective if adapted to each subgroup [2930]. Treatment according to The McKenzie method seems to reduce health care utilization [31].

Among all the patients assessed at the PAC $(n=432)$, diagnosis, gender, or being of employable age or not could not explain why some patients returned for an additional assessment by a GP within 3 months after the assessment by a physiotherapist. Perceived state 
of health or quality of care could be possible explanations. Because so few patients in the subgroup answering the questionnaire (PT-group) returned for an additional assessment by a GP after visiting the PAC $(6 / 51,12 \%)$, it was not possible to draw any conclusions.

It is important that patients trust the physiotherapist to make a correct assessment and that they receive sufficient information about the disorder and self-care if the need for additional appointments is to be reduced. Previous reports show that information about self-care is important for higher patient satisfaction [32]. Furthermore, the skill and competence of physicians, information received, and physician's explanation of illness are also of major importance for higher patient satisfaction [33]. The physiotherapist often had more time for each assessment, especially for patients with neck and back problems, which enabled a more thorough analysis of the everyday life activities of the patient. This enabled the physiotherapist to give more personal advice on how to cure or handle the disorder. This might further explain why patients assessed by a physiotherapist were more satisfied. Though generally allocation was in accordance with the guidelines, less appropriate appointments have occurred. Reduced workload for physiotherapists might be considered, for example by further development of initial assessment and advice by telephone by physiotherapists [34]. Future studies including more patients and health care centres and with randomization of the patients to primary assessment by either a physiotherapist or a GP would provide higher evidence for generalisation of the results of the current study.

\section{CONCLUSION}

Physiotherapists can be considered primary assessors of patients with musculoskeletal disorders in primary care as few patients needed additional assessment by a GP, patients with 
confirmed serious pathologies had been identified by the physiotherapist, and the patients were satisfied with the assessment by the physiotherapist.

\section{Acknowledgements}

The authors thank statistician Rita Ylikivela for statistical advice and calculations, Anna Enblom RPT, PhD and Gorel Kjellman RPT, PhD for advice, and all health care staff and patients involved in this study for participating.

Ethical approval: Following the rules of the Regional Ethical Review Board, no Ethics approval was required for the study. Participating patients received usual care; the study was an evaluation of a new practice model already in use at this facility. Local Health Authorities gave consent for the study. Patients received both oral and written information before data collection began.

Funding: The County Council of Ostergotland, Sweden

Conflict of Interest: None 


\section{REFERENCES}

[1] Hasselstrom J, Liu-Palmgren J, Rasjo-Wraak G. Prevalence of pain in general practice. Eur J Pain. 2002;6(5):375-85.

[2] Wynne-Jones G, Mallen CD, Mottram S, Main CJ, Dunn KM. Identification of UK sickness certification rates, standardised for age and sex. Br J Gen Pract. 2009 Jul;59(564):510-6.

[3] Parsons S, Breen A, Foster NE, Letley L, Pincus T, Vogel S, et al. Prevalence and comparative troublesomeness by age of musculoskeletal pain in different body locations. Fam Pract. 2007 Sep;24(4):308-16.

[4] Martin BI, Deyo RA, Mirza SK, Turner JA, Comstock BA, Hollingworth W, et al. Expenditures and health status among adults with back and neck problems. JAMA. 2008 Feb 13;299(6):656-64.

[5] Belthur MV, Clegg J, Strange A. A physiotherapy specialist clinic in paediatric orthopaedics: is it effective? Postgrad Med J. 2003 Dec;79(938):699-702.

[6] Daker-White G, Carr AJ, Harvey I, Woolhead G, Bannister G, Nelson I, et al. A randomised controlled trial. Shifting boundaries of doctors and physiotherapists in orthopaedic outpatient departments. J Epidemiol Community Health. 1999 Oct;53(10):643-50.

[7] Oldmeadow LB, Bedi HS, Burch HT, Smith JS, Leahy ES, Goldwasser M. Experienced physiotherapists as gatekeepers to hospital orthopaedic outpatient care. Med J Aust. 2007 Jun 18;186(12):625-8.

[8] Weale AE, Bannister GC. Who should see orthopaedic outpatients--physiotherapists or surgeons? Ann R Coll Surg Engl. 1995 Mar;77(2 Suppl):71-3.

[9] Holdsworth L, Webster V, McFadyen A. The Scottish Physiotherapy Self Referral Study Group. Physiotherapists' and general practitioners' views of self-referral and 
physiotherapy scope of practice: results from a national trial. Physiotherapy 2008 Sep; 94(3):236-43.

[10] McClellan CM, Greenwood R, Benger JR. Effect of an extended scope physiotherapy service on patient satisfaction and the outcome of soft tissue injuries in an adult emergency department. Emerg Med J. 2006 May;23(5):384-7.

[11] Richardson B, Shepstone L, Poland F, Mugford M, Finlayson B, Clemence N. Randomised controlled trial and cost consequences study comparing initial physiotherapy assessment and management with routine practice for selected patients in an accident and emergency department of an acute hospital. Emerg Med J. 2005 Feb;22(2):87-92.

[12] Taylor N, Noramn E, Roddy L, Tang C, Pagram A, Hearn K. Primary contact physiotherapy in emergency departments can reduce length of stay for patients with peripheral musculoskeletal injuries compared with secondary contact physiotherapy: a prospective non-randomised controlled trial. Physiotherapy Corrected Proof, Available online 17 December 2010, doi:10.1016/j.physio.2010.08.011

[13] Holdsworth LK, Webster VS. Direct accesss to physiotherapy in primary care: now? and into the future? Physiotherapy. 2004 Jun;90(2):64-72.

[14]Hefford C. McKenzie classification of mechanical spinal pain: profile of syndromes and directions of preference. Man Ther. 2008;13(1):75-81.

[15]Brazier J, Jones N, Kind P. Testing the validity of the Euroqol and comparing it with the SF-36 health survey questionnaire. Qual Life Res. 1993 Jun;2(3):169-80.

[16] van Agt HM, Essink-Bot ML, Krabbe PF, Bonsel GJ. Test-retest reliability of health state valuations collected with the EuroQol questionnaire. Soc Sci Med. 1994 Dec;39(11):1537-44. 
[17]Henschke N, Maher CG, Refshauge KM, Herbert RD, Cumming RG, Bleasel J, et al. Prevalence of and screening for serious spinal pathology in patients presenting to primary care settings with acute low back pain. Arthritis Rheum. 2009 Oct;60(10):3072-80.

[18] Ferguson F, Holdsworth L, Rafferty D. A national framework for supporting improvements in the physiotherapy assessment and management of low back pain: the Scottish experience. Physiotherapy. 2010 Sep;96(3):198-205.

[19] Holdsworth LK, Webster VS, McFadyen AK. What are the costs to NHS Scotland of self-referral to physiotherapy? Results of a national trial. Physiotherapy. 2007;93(1):3-11.

[20]Leemrijse CJ, Swinkels IC, Veenhof C. Direct access to physical therapy in the Netherlands: results from the first year in community-based physical therapy. Phys Ther. 2008 Aug;88(8):936-46.

[21] Department of Health. Self-referral pilots to musculoskeletal physiotherapy and the implications for improving access to other AHP services. London, UK 2008. Available at: http://www.dh.gov.uk/en/Publicationsandstatistics/Publications/ Publications PolicyAndGuidance/DH_089516?IdcService=GET_FILE\&dID=175274\&Rendition=We b (last accessed 03/03/2011).

[22]Frojd C, Lampic C, Larsson G, von Essen L. Is satisfaction with doctors' care related to health-related quality of life, anxiety and depression among patients with carcinoid tumours? A longitudinal report. Scand J Caring Sci. 2009 Mar;23(1):107-16.

[23] Jordan KP, Kadam UT, Hayward R, Porcheret M, Young C, Croft P. Annual consultation prevalence of regional musculoskeletal problems in primary care: an observational study. BMC Musculoskelet Disord. 2010;11:144.

[24] Allan J, Schattner P, Stocks N, Ramsay E. Does patient satisfaction of general practice change over a decade? BMC Fam Pract. 2009;10:13. 
[25] Salisbury C, Goodall S, Montgomery AA, Pickin DM, Edwards S, Sampson F, et al. Does Advanced Access improve access to primary health care? Questionnaire survey of patients. Br J Gen Pract. 2007 Aug;57(541):615-21.

[26] Webster V, Holdsworth L, McFayden A, Little H, The Scottish Physiotherapy Self Referral Study Group. Self-referral, access and physiotherapy: patient's knowledge and attitudes -results of a national trial. Physiotherapy 2008;94(2) 141-149.

[27]Enthoven P, Skargren E, Oberg B. Clinical course in patients seeking primary care for back or neck pain: a prospective 5-year follow-up of outcome and health care consumption with subgroup analysis. Spine (Phila Pa 1976). 2004 Nov 1;29(21):2458-65.

[28] Chou R, Qaseem A, Snow V, Casey D, Cross JT, Jr., Shekelle P, et al. Diagnosis and treatment of low back pain: a joint clinical practice guideline from the American College of Physicians and the American Pain Society. Ann Intern Med. 2007 Oct 2;147(7):47891.

[29]Brennan GP, Fritz JM, Hunter SJ, Thackeray A, Delitto A, Erhard RE. Identifying subgroups of patients with acute/subacute "nonspecific" low back pain: results of a randomized clinical trial. Spine (Phila Pa 1976). 2006 Mar 15;31(6):623-31.

[30]Fritz JM, Whitman JM, Childs JD. Lumbar spine segmental mobility assessment: an examination of validity for determining intervention strategies in patients with low back pain. Arch Phys Med Rehabil. 2005 Sep;86(9):1745-52.

[31] Machado LA, Maher CG, Herbert RD, Clare H, McAuley JH. The effectiveness of the McKenzie method in addition to first-line care for acute low back pain: a randomized controlled trial. BMC Med. 2010;8:10.

[32] Muntlin A, Gunningberg L, Carlsson M. Patients' perceptions of quality of care at an emergency department and identification of areas for quality improvement. J Clin Nurs. 2006 Aug;15(8):1045-56. 
[33] Krishel S, Baraff LJ. Effect of emergency department information on patient satisfaction. Ann Emerg Med. 1993 Mar;22(3):568-72.

[34] Foster NE, Williams B, Grove S, Gamlin J, Salisbury C. The evidence for and against 'PhysioDirect' telephone assessment and advice services. Physiotherapy. 2011 Mar;97(1):78-82. 


\section{References search strategy}

Databases searched were Databases: Medline, Cinahl, Pedro, Cochrane and Amed. Search terms used were: physical therapist or physiotherapist, assessment or examination, musculoskeletal or low back or cervical/neck, physician or GP or orthopedic, Euroqol, prevalence, primary care, patient satisfaction. Last search was performed March 8, 2011. 